\title{
Efeito da aplicação de fungicidas no controle de doenças foliares de arroz irrigado e sua relação com o rendimento industrial
}

\author{
Luiz Carlos Bordin ${ }^{1 *}$, Ricardo Trezzi Casa ${ }^{2}$, Leandro Luiz Marcuzzo ${ }^{1}$, Amauri Bogo ${ }^{2}$, Rômulo Luis Zancam ${ }^{3}$
}

${ }^{1}$ Professor do Instituto Federal Catarinense - IFC/Campus Rio do Sul CP 441, CEP 89163-356, Rio do Sul, SC; ${ }^{2}$ Professores do Departamento de Agronomia do Centro de Ciências Agroveterinárias - CAV/UDESC. Bolsistas de Produtividade em Pesquisa do CNPq; ${ }^{3}$ Aluno de graduação do curso de Agronomia do Centro de Ciências Agroveterinárias - CAV/UDESC. Bolsista de Iniciação Científica - PIBIC/CNPq; *Parte da tese de doutorado do primeiro autor.

Autor para correspondência: Luiz Carlos Bordin (luizcarlosbordin@ifc-riodosul.edu.br)

Data de chegada: 27/05/2014. Aceito para publicação em: 26/08/2015.

$10.1590 / 0100-5405 / 2012$

\section{RESUMO}

Bordin, L.C.; Casa, R.T.; Marcuzzo, L.L.; Bogo, A.; Zancan, R.L. Efeito da aplicação de fungicidas no controle de doenças foliares de arroz irrigado e sua relação com o rendimento industrial. Summa Phytopathologica, v.42, n.1, p.85-88, 2016.

As doenças foliares do arroz podem comprometer o enchimento e a maturação dos grãos por acelerar a sua secagem e, consequentemente, reduzir o rendimento industrial. O uso de fungicida tem o potencial de reduzir os danos das doenças foliares da cultura e aumentar o rendimento industrial. O objetivo deste trabalho foi avaliar o número de aplicação de fungicida em diferentes estádios fenológicos no controle de doenças foliares para o patossistema múltiplo (brusone, mancha parda e escaldadura) e sua relação com o rendimento industrial (rendimento de benefício, grãos inteiros e grãos quebrados). Os experimentos foram conduzidos nas safras agrícolas 2011/12 e 2012/13 no município de Rio do Oeste, localizado no Alto Vale do Itajaí, estado de Santa Catarina. Nos experimentos foi utilizada a cultivar SCS 116 Satoru. O delineamento foi de blocos casualizados, com quatro repetições e seis tratamentos constituídos de aplicações de mistura de fungicida difenoconazol e azoxistrobina, sendo um dos tratamentos (testemunha) sem aplicação. As aplicações de fungicidas foram feita no estádio vegetativo V8 e nos reprodutivos R0, R2, R4 e R6. A colheita foi de forma manual, colhendo-se $2 \mathrm{~m}^{2}$ da área central de cada parcela. Uma, duas, três, quatro e cinco aplicações de fungicida apresentaram incremento médio em relação á testemunha nas duas safras, de $6 \%, 7,2 \%, 13,1 \%, 17,4 \%$ e $19,2 \%$ no rendimento debenefício, $14,6 \%, 28,5 \%, 36,1 \%, 45 \%$ e $48,7 \%$ para grãos inteiros e reduziu o percentual de grãos quebrados em $4,4 \%, 13,2 \%, 21,7 \%$, $35 \%$ e $41,4,1 \%$, respectivamente.

Palavras-chave: Oryza sativa, doenças foliares, severidade foliar, rendimento de benefício.

\section{ABSTRACT}

Bordin, L.C.; Casa, R.T.; Marcuzzo, L.L.; Bogo, A.; Zancan, R.L. Effect of fungicide application on the control of leaf diseases of irrigated rice and its relationship with industrial yield. Summa Phytopathologica, v.42, n.1, p.85-88, 2016.

Leaf diseases of rice can compromise grain filling and spikelet maturation for accelerating the drying of grains and, consequently, reducing the industrial yield. The use of fungicide has the potential to reduce the damage from leaf diseases and increase the industrial yield. The aim of this study was to evaluate the number of fungicide application at different growth stages on the control of leaf diseases for multiple pathosystem (blast, brown spot and scald) and its relationship with the industrial yield (income benefit, whole and broken grains). The experiments were conducted in the growing seasons 2011/12 and 2012/13 in Rio do Oeste County, located at Alto Vale do Itajaí, Santa Catarina State. Rice cultivar SCS 116 Satoru was used. Experimental design was in randomized blocks with four replicates and six treatments constituted of applications of a mixture of fungicides difenoconazole and azoxystrobin, while one of the treatments (control) received no chemical application. Fungicide applications were performed at $\mathrm{V} 8$ vegetative stage and at the reproductive stages R0, R2, R4 and R6. Harvest was manually performed, obtaining $2 \mathrm{~m}^{2}$ of the central area of each plot. One, two, three, four and five fungicide applications showed an average increase, compared to the control, in the two seasons, of $6 \%, 7.2 \%$, $13.1 \%, 17.4 \%$ and $19.2 \%$ of the income benefit, $14.6 \%, 28.5 \%, 36.1 \%, 45 \%$ and $48.7 \%$ for whole grains, while the percentage of broken grains reduced by $4.4 \%, 13.2 \%, 21.7 \%, 35 \%$ and $41.4 \%$, respectively.

Keywords: Oryza sativa, leaf diseases, leaf severity, income benefit.

O arroz (Oryza sativa L.) destaca-se como alimento básico para mais da metade da população mundial. É cultivado em todos os continentes, desempenhando papel estratégico no aspecto econômico e social (3). O Brasil é o nono produtor mundial com área aproximadamente de 2,4 milhões de hectares e produção de 11,9 milhões de toneladas (5).

Os aspectos ligados à qualidade de grãos em arroz são amplos e complexos por ser consumido principalmente na forma de grãos inteiros, descascados e polidos. O que determina o valor comercial do arroz é a qualidade industrial dos grãos, principalmente a percentagem de grãos inteiros. Este valor é obtido em função do rendimento de benefício, que é determinado pela relação entre as quantidades de grãos inteiros e quebrado após o beneficiamento dos grãos com casca. Os danos mecânicos nos grãos ocorrem pela ação de diversos estresses bióticos e abióticos, como falta ou excesso de chuvas, ataque de pragas, doenças, entre outros (4).

Os programas de melhoramento genético buscam introduzir cultivares de arroz com alta produtividade, mas que também apresentam qualidade de grãos e melhor rendimento industrial. $\mathrm{O}$ 
incremento destas qualidades visa principalmente o alto rendimento de grãos inteiros no beneficiamento, porém, estes fatores podem ser afetados pela suscetibilidade do genótipo e condições climáticas favoráveis à ocorrência de doenças (16).

Em consequência da inexistência de material genético resistente a doenças fúngicas e o uso intensificado das áreas de cultivo, problemas sanitários foram criados e segundo Prabhu et al. (14), as doenças causadas por fungos são os principais problemas da orizicultura mundial.

Dentre as principais doenças fúngicas da cultura nas regiões produtoras de arroz irrigado no estado do Rio Grande do Sul e Santa Catarina, que podem prejudicar a produtividade e a qualidade dos grãos colhidos, destacam-se a brusone [Pyricularia grisea (Cooke) Saccardo], mancha parda [Bipolaris oryzae (Breda de Hann) Shoemaker], mancha estreita [Cercospora janseana (Racib) O. Const.] e escaldadura [Gerlachia oryzae (Hashioka\&Yokogi) W. Gams] (17).

Segundo Castro et al. (4) as doenças fúngicas reduzem a qualidade do arroz causando manchas-nos-grãos ou por comprometer o seu enchimento e maturação. Isto acontece por acelerar a secagem dos grãos nas plantas infectadas, predispondo-os à maior incidência de rachaduras quando ainda no campo e, consequentemente, à maior quebra de grãos no beneficiamento.

Em muitos casos, o controle químico é eficiente, economicamente viável e capaz de garantir maior produtividade e qualidade de produção $(12,13,17)$. Segundo Miura et al. (11) o manejo de doenças fúngicas pelo uso de fungicidas pode reduzir danos no percentual de grãos inteiros, sendo importante avaliar o efeito do fungicida na qualidade física dos grãos de arroz. Consideram ainda que o rendimento industrial é um instrumento como indicador da eficiência de fungicidas.

As indicações técnicas do arroz (17) recomendam para melhorar o rendimento de grãos inteiros, duas aplicações de fungicidas durante os estádios de emborrachamento tardio (até 5\% de emissão de panículas) e a segunda, 10-15 dias após. Porém, o uso eficiente de qualquer programa de manejo integrado de doenças requer informação precisa e acurada da relação entre intensidade da doença e os danos causados.

O objetivo deste trabalho foi avaliar o número de aplicação de fungicida em diferentes estádios fenológicos no controle de doenças foliares de arroz irrigado para o patossistema múltiplo (brusone, mancha parda e escaldadura) e sua relação com o rendimento industrial (rendimento de benefício, grãos inteiros e grãos quebrados).

\section{MATERIAL E MÉTODOS}

Os experimentos foram instalados em lavouras comerciais no município de Rio do Oeste, Alto Vale do Itajaí, estado de Santa Catarina, durante as safras 2011/12 e 2012/13. As coordenadas geográficas situam-se em $27^{\circ} 11^{\prime} 33^{\prime \prime}$ de latitude sul, $49^{\circ} 47^{\prime} 48^{\prime}$ 'de longitude oeste e altitude de 365 metros (8).

Na semeadura foi utilizado o cultivar de arroz SCS116 Satoru, cujas características são ciclo tardio (de 136 a 159 dias da semeadura à maturação), medianamente resistente à brusone e sem informação para as demais doenças fúngicas. A semeadura foi no sistema pré-germinado na densidade de $150 \mathrm{~kg} \mathrm{ha}^{-1}$ (17).

As adubações de base, a aplicação de adubação nitrogenada, bem como, o controle de plantas invasoras e pragas foram realizadas de acordo com as recomendações técnicas para a cultura do arroz no sul do país (17).

Os experimentos foram conduzidos com delineamento experimental em blocos casualisados. Foram realizados seis tratamentos constituídos de aplicações de mistura de fungicidas triazol (difenoconazol) e estrobilurina (azoxistrobina) $\left(0,2+0,4 \mathrm{~L} \mathrm{ha}^{-1}\right.$ p.c.), mais óleo mineral (Nimbus) (0,5 L ha ${ }^{-1}$ p.c.), dose indicada pelo fabricante, com quatro repetições, totalizando 24 parcelas por experimento, sendo um dos tratamentos (testemunha) sem aplicação de fungicida. A área correspondente a cada unidade experimental foi de $12,5 \mathrm{~m}^{2}$.

Os fungicidas foram aplicados em intervalos de 15 a 20 dias, pelo uso de pulverizador costal de pressão constante gerado por gás $\mathrm{CO}_{2}$ com barra de dois metros de comprimento e seis bicos de pulverização, com volume de calda de 200 litros ha ${ }^{-1}$.

As aplicações de fungicidas ocorreram nos estádios perfilhamento (V8), iniciação da panícula (R0), emborrachamento (R2), floração (R4) e grão leitoso (R6), de acordo com a escala de Counce et al. (7). Aplicação fungicida: uma aplicação (V8), duas aplicações (V8 + R0), três aplicações (V8 + R0 + R2), quatro aplicações (V8 + R0 + R2 + R4) e cinco aplicações (V8 + R0 + R2 + R4 + R6).

As coletas para avaliação da severidade das doenças foliares foram realizadas sempre antes de cada aplicação de fungicida, destacando-se 30 folhas expandidas, em 10 plantas, uma folha do extrato inferior, uma do mediano e uma do superior ao acaso de cada parcela experimental, sendo desconsideradas as folhas em fase de expansão e senescidas.

Considera-se severidade foliar o percentual de área de tecido afetado pela doença $(2,15,19)$. Para a quantificação da severidade das doenças foliares, considerando o patossistema múltiplo (brusone, mancha parda e escaldadura), duas pessoas treinadas foram responsáveis pela avaliação em todas as amostras coletadas para evitar possíveis erros sistemáticos, com auxílio de escala diagramática para bruzone (1), mancha parda (10) e escaldadura (9).

A colheita foi manual, coletando-se $2 \mathrm{~m}^{2}$ da parte central de cada parcela. A trilha e a limpeza foram realizadas em máquina estacionária e os grãos em estufa até atingir umidade de $13 \%$.

O rendimento industrial dos grãos foi realizado em uma amostra de $100 \mathrm{~g}$ de cada parcela, isenta de matérias estranhas e impurezas, submetida ao beneficiamento, em um mini engenho, Modelo MT 86 Suzuki, para o descascamento e brunimento da amostra. A separação dos grãos inteiros (rendimento dos grãos) e quebrados foi realizada no "trieur" (classificador portátil de cereais, Modelo Tipo C.R.Z.). O percentual de grãos inteiros e quebrados foi obtido de forma direta, pela pesagem dos grãos. $\mathrm{O}$ rendimento de beneficiamento, que significa o percentual entre grãos com casca e grãos descascados, também foi obtida de maneira direta, através da soma do percentual de grãos inteiros e de grãos quebrados.

Os resultados obtidos referentes ao número de aplicações de fungicida e sua relação com o rendimento industrial, foram submetidos à análise de variância e as médias comparadas pelo teste de Tukey $(\mathrm{P}<0,05)$, pelo uso do programa estatístico SAS versão 9.2.

\section{RESULTADOS E DISCUSSÃO}

Em ambas as safras agrícolas ocorreram doenças foliares observadas na fase vegetativa da cultura a partir da primeira aplicação de fungicida. Estes dados permitiram determinar a intensidade da doença, indicando uma severidade inicial média de $0,33 \%$ e $0,48 \%$, para as safras $2011 / 12$ e 2012/13, respectivamente.

Também houve ocorrência concomitante da brusone, mancha parda e escaldadura (patossistema múltiplo), com predominância da brusone nas duas safras. A ocorrência de doenças causadas por patógenos necrotróficos nesta região, pode ser em função de que a cultura do arroz é cultivada no sistema de monocultura. Segundo Reis \& Casa 
(15) esta prática mantém e aumenta o inóculo a uma densidade tal que, dependendo das condições climáticas, poderão ocorrer epidemias de doenças fúngicas na lavoura.

A severidade foliar na safra 2012/13 foi superior (média $=1,29 \%$ a $5,25 \%$ ) (Tabela 2) a da safra anterior (média $=0,30 \%$ a 1,34\%) (Tabela 1) em virtude das condições climáticas de baixa luminosidade causada pela nebulosidade e molhamento foliar caracterizado pela alta umidade relativa que ocorrem na região do Alto Vale do Itajaí. São características que determinam que algumas doenças sejam mais agressivas que outras em diferentes regiões e em diferentes safras (Tabela 1).

Em ambas as safras e ensaios, houve efeito significativo $(\mathrm{P}<0,05)$ entre a severidade das doenças foliares e rendimento industrial (rendimento de benefício, percentagem de grãos inteiros e grãos quebrados) em relação à resposta ao número de aplicação de fungicida.

Desta forma, evidenciou-se que o número de aplicações de fungicidas resultou em aumento no rendimento industrial e isto pode ter ocorrido pela redução da severidade foliar.

Os tratamentos com menor severidade de doenças foliares apresentaram maior percentual de rendimento industrial. A média dos ensaios para o rendimento de benefício foi de $53,5 \%$ a $68 \%$ e $56 \%$ a $67,5 \%$, para grãos inteiros de $27 \%$ a $54,5 \%$ e $24 \%$ a $45,5 \%$ e para grãos quebrados, $26,5 \%$ a $13 \%$ e $32,5 \%$ a $22 \%$,nas safras 2011/12 e 2012/13, respectivamente (Tabela 1, Tabela 2 e Tabela 3 ).

Os padrões das Normas Específicas de Arroz consideram percentuais de $68 \%$ de rendimento de benefício, sendo $58 \%$ grãos inteiros e $10 \%$ de grãos quebrados. Para aquisição do Governo Federal (AGV) é importante ressaltar que o arroz sofre um deságio por quilo para cada percentual que esteja abaixo dos padrões estabelecidos. De acordo com esses valores, atingiram-se apenas para o rendimento de benefício, com 4 e 5 aplicações de fungicidas (safra 2011/12) e com 5 aplicações de fungicidas (safra 2012/13). Para grãos inteiros e quebrados os valores ficaram abaixo do padrão estabelecido (6) (Tabela 2 e Tabela 3).

Para grãos inteiros que é utilizado o percentual para o estabelecimento do preço no momento da comercialização, o melhor resultado foi de 54,5\% na safra de 2011/12. Em trabalho realizado por Miura et al. (11) também relatam perdas no percentual de grãos inteiros no cultivar de arroz IRGA 422 provocado pela ocorrência de doenças fúngicas. Teló et al. (18) encontraram interação significativa para percentuais de grãos inteiros entre os cultivares BR-IRGA 409 e IRGA 423 com aplicações de fungicidas.

Em relação aos grãos quebrados, os melhores resultados obtidos foram 5 e 6 aplicações de fungicidas na safra 2011/12, com média de $16 \%$ e $13 \%$, respectivamente. Já para safra 2012/13 não houve a mesma resposta. Isto pode ser em consequência da maior severidade de doenças foliares, com média dos tratamentos de 2,9\% (Tabela 1 , Tabela 2 e Tabela 3). Segundo Castro et al. (4) em plantas infectadas ocorre à aceleração da maturação das espiguetas e a secagem dos grãos,

Tabela 1. Severidade de doenças foliares avaliadas nas folhas em resposta a aplicação de fungicida, cultivar SCS 116 Satoru, ensaio 1 e 2 , nas safras agrícolas 2011/12 e 2012/13, em Rio do Oeste, Alto Vale do Itajaí, SC

\begin{tabular}{|c|c|c|c|c|c|c|}
\hline \multirow[b]{3}{*}{ Tratamentos } & \multicolumn{6}{|c|}{ Severidade $^{1}(\%)$} \\
\hline & \multicolumn{3}{|c|}{ Safra 2011/12 } & \multicolumn{3}{|c|}{ Safra $2012 / 13$} \\
\hline & \multicolumn{2}{|c|}{ Ensaio } & Média & \multicolumn{3}{|c|}{ Ensaio } \\
\hline $\mathrm{T} 1$ & $1,17 \mathrm{a}$ & $1,51 \mathrm{a}$ & $1,34 \mathrm{a}$ & $5,82 \mathrm{a}$ & $4,67 \mathrm{a}$ & $5,25 \mathrm{a}$ \\
\hline $\mathrm{T} 2$ & $0,75 \mathrm{~b}$ & $0,80 \mathrm{~b}$ & $0,78 \mathrm{~b}$ & $4,06 \mathrm{~b}$ & $3,28 \mathrm{~b}$ & $3,67 \mathrm{~b}$ \\
\hline $\mathrm{T} 3$ & $0,68 \mathrm{~b}$ & $0,61 \mathrm{~b}$ & $0,65 \mathrm{c}$ & $3,07 \mathrm{c}$ & $2,67 \mathrm{~b}$ & $2,87 \mathrm{bc}$ \\
\hline $\mathrm{T} 5$ & $0,43 \mathrm{c}$ & $0,44 \mathrm{c}$ & $0,44 \mathrm{~d}$ & $2,21 \mathrm{c}$ & $1,79 \mathrm{c}$ & $2,00 \mathrm{cc}$ \\
\hline T6 & $0,28 \mathrm{~d}$ & $0,32 \mathrm{c}$ & $0,30 \mathrm{e}$ & $1,23 \mathrm{~d}$ & $1,34 \mathrm{c}$ & $1,29 \mathrm{~d}$ \\
\hline
\end{tabular}

Médias seguidas de mesma letra não diferem entre si pelo teste de Tukey, ao nível de $5 \%$ de probabilidade.

Aplicação fungicida: T1 = testemunha (sem aplicação de fungicida); T2 = uma aplicação (V8); T3 = duas aplicações (V8 + R0); T4 = três aplicações (V8 + R0 + R2); T5 = quatro aplicações $(\mathrm{V} 8+\mathrm{R} 0+\mathrm{R} 2+\mathrm{R} 4) ; \mathrm{T} 6=$ cinco aplicações $(\mathrm{V} 8+\mathrm{R} 0+\mathrm{R} 2+\mathrm{R} 4+\mathrm{R} 6)$.

${ }^{1}$ Severidade: brusone, mancha parda e escaldadura.

Tabela 2. Qualidade industrial: percentagem de rendimento de benefício, grãos inteiros e grãos quebrados do cultivar SCS 116 Satoru em resposta à aplicação de fungicidas, ensaio 1 e 2, na safra agrícola de 2011/12, em Rio do Oeste, Alto Vale do Itajaí, SC

\begin{tabular}{|c|c|c|c|c|c|c|}
\hline \multirow[b]{2}{*}{ Tratamentos } & \multicolumn{3}{|c|}{ Ensaio 1} & \multicolumn{3}{|c|}{ Ensaio 2} \\
\hline & Benefício & Inteiros & Quebrados & Benefício & Inteiros & Quebrados \\
\hline $\mathrm{T} 1$ & $56 \mathrm{e}$ & $30 \mathrm{f}$ & $26 \mathrm{a}$ & $51 \mathrm{~d}$ & $24 \mathrm{~d}$ & $27 \mathrm{a}$ \\
\hline $\mathrm{T} 3$ & $63 \mathrm{c}$ & $41 \mathrm{~d}$ & $22 \mathrm{~b}$ & $57 \mathrm{c}$ & $32 \mathrm{c}$ & $25 \mathrm{a}$ \\
\hline $\mathrm{T} 4$ & $65 \mathrm{~b}$ & $43 \mathrm{c}$ & $22 \mathrm{~b}$ & $61 \mathrm{~b}$ & $40 \mathrm{~b}$ & $21 \mathrm{~b}$ \\
\hline Média & 63 & 42 & 21 & 59 & 38 & 21 \\
\hline C.V. $(\%)$ & 1,92 & 1,78 & 3,84 & 1,97 & 6,04 & 7,87 \\
\hline
\end{tabular}

Médias seguidas de mesma letra não diferem entre si pelo teste de Tukey, ao nível de $5 \%$ de probabilidade.

Aplicação fungicida: T1 = testemunha (sem aplicação de fungicida); T2 = uma aplicação (V8); T3 = duas aplicações (V8 + R0); T4 = três aplicações (V8 + R0 + R2); T5 = quatro aplicações $(\mathrm{V} 8+\mathrm{R} 0+\mathrm{R} 2+\mathrm{R} 4) ; \mathrm{T} 6=$ cinco aplicações $(\mathrm{V} 8+\mathrm{R} 0+\mathrm{R} 2+\mathrm{R} 4+\mathrm{R} 6)$. 
Tabela 3. Qualidade industrial: percentagem de rendimento de benefício, grãos inteiros e grãos quebrados do cultivar SCS 116 Satoru (ensaio 1 e 2), em resposta à aplicação de fungicidas, na safra agrícola de 2012/13, em Rio do Oeste, Alto Vale do Itajaí, Santa Catarina

\begin{tabular}{|c|c|c|c|c|c|c|}
\hline \multirow[b]{2}{*}{ Tratamentos } & \multicolumn{3}{|c|}{ Ensaio 1} & \multicolumn{3}{|c|}{ Ensaio 2} \\
\hline & Benefício & Inteiros & Quebrados & Benefício & Inteiros & Quebrados \\
\hline $\mathrm{T} 1$ & $55 \mathrm{~d}$ & $20 \mathrm{c}$ & $35 \mathrm{a}$ & $57 \mathrm{~b}$ & $28 \mathrm{c}$ & $30 \mathrm{a}$ \\
\hline $\mathrm{T} 3$ & $61 \mathrm{c}$ & $31 \mathrm{c}$ & $30 \mathrm{ab}$ & $61 \mathrm{ab}$ & $38 \mathrm{~b}$ & $26 \mathrm{ab}$ \\
\hline $\mathrm{T} 4$ & $63 \mathrm{bc}$ & $37 \mathrm{~b}$ & $26 \mathrm{bc}$ & $63 \mathrm{a}$ & $39 \mathrm{~b}$ & $23 \mathrm{~b}$ \\
\hline Média & 62 & 34 & 28 & 62 & 37 & 25 \\
\hline C.V. (\%) & 2,97 & 4,85 & 7,71 & 3,73 & 6,04 & 7,76 \\
\hline
\end{tabular}

Médias seguidas de mesma letra não diferem entre si pelo teste de Tukey, ao nível de $5 \%$ de probabilidade.

Aplicação fungicida: T1 = testemunha (sem aplicação de fungicida); T2 = uma aplicação (V8); T3 = duas aplicações (V8 + R0); T4 = três aplicações (V8 + R0 + R2); T5 = quatro aplicações (V8 + R0 + R2 + R4); T6 = cinco aplicações (V8 + R0 + R2 + R4 + R6).

os grãos mais secos das panículas lesionadas podem apresentar teor de umidade até $5 \%$ a menos que os das sadias, ficam muito vulneráveis aos efeitos do ambiente, predispondo-os a maior incidência de rachaduras quando ainda no campo e, consequentemente, à maior quebra de grãos no beneficiamento.

A aplicação de fungicidas em diferentes estádios fenológicos da cultura do arroz irrigado, respeitando o intervalo de persistência do fungicida, proporcionou melhores percentagens para o rendimento industrial (rendimento de benefício, grãos inteiros e grãos quebrados) do cultivar de arroz irrigado SCS 116 Satoru, na região do Alto Vale do Itajaí, estado de Santa Catarina.

\section{REFERÊNCIAS BIBLIOGRÁFICAS}

1. Azevedo, L.A.S. Manual de quantificação de doenças de plantas. São Paulo: Novartis Biociências, 1997. 11 p.

2. Bergamin Filho, A.; Amorin, L. Doenças de plantas tropicais: epidemiologia e controle econômico. São Paulo: Agronômica Ceres, 1996. 289 p.

3. Bortolotto, R.P.; Menezes, N.L.; Garcia, D. C.; Mattioni, N.M. Teor de proteína e qualidade fisiológica de sementes de arroz. Bragantia, Campinas, v.67, n.2, p.513-518, 2008

4. Castro, E.M.; Vieira, N.R.A.; Rabelo, R.R.; Silva, S.A. Qualidade de grãos em arroz. Embrapa Arroz e Feijão, Santo Antônio de Goiás, 1999, 30p. (Circular Técnica, 34).

5. Conab. Companhia Nacional de Abastecimento. Acompanhamento de safra brasileira: grãos, $9^{\circ}$ levantamento, Brasília, 2013a.

6. Conab. Companhia Nacional de Abastecimento. Normas Específicas de Arroz. Disponível em: <http://www.conab.gov.br/>. Acesso em: 06 abr. $2014 b$.

7. Counce, P.; Keisling, T.C.; Mitchell, A.J. A uniform, objective, and adaptive system for expressing rice development. Crop Science, Madison, v.40, n.2, p.436-443, 2000.

8. Epagri. Atlas climatológico do estado de Santa Catarina. Online. Flo- rianópolis: Disponível em: http://ciram.epagri.sc.gov.br/portal/website/ Acesso em: 06 abr. 2014

9. International Rice Research Institute. Standard evaluation system for rice. $4^{\text {nd }}$ ed. Manila. 1996. 52 p.

10. Lenz, G.; Balardin, R.S.; Dala Corte, G.; Marques, L.N.; Debona, D. Escala diagramática para avaliação de severidade de mancha-parda em arroz. Ciência Rural, Santa Maria, v.40, n.4, p.752-758, 2010.

11. Miura, L.; Peruch, L.A.M.; Silva, C.M. Épocas de aplicação e rendimento de grãos inteiros determinam a eficiência de fungicidas no controle da brusone. In: CONGRESSO BRASILEIRO DE ARROZ IRRIGADO, 4. 2005, Santa Maria - RS, Anais... Santa Maria: UFSM, 2005. p.517-519.

12. Pommel, B.; Gallais, A.; Coque, M.; Quillere, L.; Hirel, B.; Prioul, J.L.; Andrieu, B. Carbon and nitrogen allocation and grain filling in three maize hybrids differing in leaf senescence. Journal of Agronomy, Cairo, v.24, n.3, p.203-211, 2006.

13. Prabhu, A.S.; Filippi, M.C.; Zimmermann, F.J.P. Cultivar response to fungicide application in relation to rice blast control, Pesquisa Agropecuária Brasileira, Brasília, v.38, n.1, p.11-17, jan. 2003.

14. Prabhu, A.S.; Filippi, M.C.C.; Ribeiro, A.S. Doenças e seu controle. In: Santos, A.B.; Stone, L.F.; Vieira, N.R.A. (Ed.). A cultura do arroz no Brasil. Santo Antônio de Goiás: EMBRAPA/CNPAF, 2.ed. 2006. p.561-590.

15. Reis, E.M.; Casa, R.T. Doenças dos Cereais de Inverno: diagnose, epidemiologia e controle. 2 ed. Ver. atual. Lages: Graphel, 2007. 176p.

16. Soares, A.A.; Conélio, V.M. de O.; Reis, M.S.; Soares, P.C.; Santos, P.G.; Souza, M.A. Desempenho de linhagens de arroz de terras altas quanto à produtividade de grãos e outras características em Minas Gerais. Revista Ceres, Viçosa, v.50, p. 509-525, 2003.

17. Sosbai. Arroz Irrigado: recomendações técnicas da pesquisa para o Sul do Brasil. Sociedade Sul-Brasileira de Arroz Irrigado, XXIX Reue nião Técnica da Cultura do Arroz Irrigado. Itajaí, 2012. 179p.

18. Teló, G.M.; Marchezan, E.; Ferreira, R.B.; Menezes, N.L.; Hansel, D.S.S.; Sartori, G.M.S. Aplicação de fungicida em plantas de arroz irrigado e seu efeito na qualidade de sementes durante o armazenamento. Revista Brasileira de Sementes, Londrina, v. 34, n.1, 2012.

19. Vale, F.X.R.; Jesus Junior, W.C.; Zambolim, L. Epidemiologia aplicada ao manejo de doenças de plantas. Belo Horizonte: Editora Perfil, 2004. $531 \mathrm{p}$. 